NBER WORKING PAPER SERIES

\title{
ADVANCED PURCHASE COMMITMENTS FOR A MALARIA VACCINE: ESTIMATING COSTS AND EFFECTIVENESS
}

\author{
Ernst R. Berndt \\ Rachel Glennerster \\ Michael R. Kremer \\ Jean Lee \\ Ruth Levine \\ Georg Weizsäcker \\ Heidi Williams \\ Working Paper 11288 \\ http://www.nber.org/papers/w11288 \\ NATIONAL BUREAU OF ECONOMIC RESEARCH \\ 1050 Massachusetts Avenue \\ Cambridge, MA 02138 \\ April 2005
}

We thank Pia Bruce, Iain Cockburn, Joseph DiMasi, Amy Finkelstein, Heather Freeman, Henry Grabowski, Hannah Kettler, Andrew Metrick, and Blair Sachs for their helpful comments and input, as well as other participants in the Pull Mechanisms Working Group of the Global Health Policy Research Network, a program of the Center for Global Development that is supported by the Bill \& Melinda Gates Foundation. We are especially grateful to Henry Grabowski for his generosity in sharing the pharmaceutical sales revenue data with us. All errors and opinions are those of the authors. The views expressed herein are those of the author(s) and do not necessarily reflect the views of the National Bureau of Economic Research.

(C2005 by Ernst R. Berndt, Rachel Glennerster, Michael R. Kremer, Jean Lee, Ruth Levine, Georg Weizsäcker, and Heidi Williams. All rights reserved. Short sections of text, not to exceed two paragraphs, may be quoted without explicit permission provided that full credit, including (C) notice, is given to the source. 
Advanced Purchase Commitments for a Malaria Vaccine: Estimating Costs and Effectiveness

Ernst R. Berndt, Rachel Glennerster, Michael R. Kremer, Jean Lee, Ruth Levine, Georg

Weizsäcker, and Heidi Williams

NBER Working Paper No. 11288

April 2005, Revised July 2006

JEL No. I18, O19, O31, O38

\begin{abstract}
$\underline{\text { ABSTRACT }}$
To overcome the problem of insufficient research and development $(R \& D)$ on vaccines for diseases concentrated in low-income countries, sponsors could commit to purchase viable vaccines if and when they are developed. One or more sponsors would commit to a minimum price that would be paid per person immunized for an eligible product, up to a certain number of individuals immunized. For additional purchases, the price would eventually drop to short-run marginal cost. If no suitable product were developed, no payments would be made. We estimate the offer size which would make the revenues from $R \& D$ investments on a malaria vaccine similar to revenues realized from investments in typical existing commercial pharmaceutical products, as well as the degree to which various contract models and assumptions would affect the cost-effectiveness of such a commitment for the case of a malaria vaccine. Under conservative assumptions, we document that the intervention would be highly cost-effective from a public health perspective. Sensitivity analyses suggest most characteristics of a hypothetical malaria vaccine would have little effect on the cost-effectiveness, but that the duration of protection against malaria conferred by a vaccine strongly affects potential cost-effectiveness. Readers can conduct their own sensitivity analyses employing a web-based spreadsheet tool.

Ernst R. Berndt

Sloan School of Management

MIT, E52-452

50 Memorial Drive

Cambridge, MA 02142

and NBER

eberndt@mit.edu

Rachel Glennerster

MIT Poverty Action Lab

Michael R. Kremer

Harvard University

Department of Economics

Littauer Center 207

Cambridge, MA 02138

and NBER

mkremer@fas.harvard.edu

Jean Lee

Harvard University

Ruth Levine

Center for Global Development

Georg Weizsäcker

London School of Economics

Heidi Williams

Research Assistant, NBER
\end{abstract}




\section{Introduction}

Compared to the social need, there is a dearth of research and development (R\&D) on vaccines for diseases concentrated in low-income countries. One commonly cited estimate is that half of all global health R\&D in 1992 was undertaken by private industry - but that less than five percent of that was spent on diseases specific to poor countries (WHO, 1996).

Biotechnology and pharmaceutical (“biopharmaceutical”) firms that operate under a profitmaximizing business model are likely reluctant to invest in R\&D for such diseases if they fear they may be unable to sell a vaccine at prices that would cover their risk-adjusted costs. Low anticipated prices reflect both the poverty of the relevant populations as well as at least two severe distortions in markets for vaccines for these diseases.

First, governments and other institutions that buy vaccines for these diseases (such as bilateral and multilateral aid agencies) face a time-inconsistency problem. Once biopharmaceutical companies have invested in the $R \& D$ necessary to develop vaccines, governments and international organizations often use their powers as dominant purchasers and arbiters of intellectual property rights to keep prices close to marginal cost. Because the largest part of the industry's expenditures lies in the initial R\&D cost (while the variable costs of production are typically modest), nearmarginal cost pricing likely implies negative total profits from the investment, thereby deterring industry from investing in the first place.

Second, the knowledge generated by research on these diseases is an international public good. Because the benefits of scientific and technological advances spill over to many nations, none of the many small countries that would benefit from vaccines for diseases like malaria, tuberculosis, or HIV have an incentive to encourage research by unilaterally offering to pay higher prices. 
One proposal which could potentially address both market failures would be for purchasers (for example, foreign aid donors) to undertake advance market commitments for desired vaccines to commit, in advance of product development and licensure, to fully or partially finance vaccine purchases for poor countries at a pre-specified price. As we discuss in Section 2, such commitments could create market incentives for firms to develop needed vaccines. If no vaccine is developed, no donor funds would be spent.

This type of policy initiative has recently been gathering momentum. A working group convened by the Center for Global Development in Washington, DC, with financial support from the Bill \& Melinda Gates Foundation, recently released a report exploring the details of how such a commitment could be implemented (Barder et al., 2005). In November 2004 Britain’s Chancellor of the Exchequer, Gordon Brown, announced that the UK government, working in cooperation with other donors, would be willing to enter into an advance market commitment for a malaria vaccine (Brown, 2004); the Chancellor later announced that the UK will also explore the use of advance market commitments for HIV vaccines. In December 2005 the G7 finance ministers announced an agreement to work with others on developing a pilot advance market commitment (HM Treasury, 2005), and further statements of support were issued by several countries at the July 2006 G8 Summit in St. Petersburg, Russia (G8 Information Centre, 2006).

In this article, we first provide a brief background on the structure of advance market commitments (Section 2). We then estimate what size of a commitment would provide a market comparable to those of existing biopharmaceuticals (Section 3), discuss the cost-effectiveness of commitments for vaccines against three diseases concentrated in low-income countries (malaria, tuberculosis, and HIV/AIDS) (Section 4), and conduct sensitivity analyses of such commitments under various contract models and assumptions (Section 5). 
To preview our results, we find that a commitment to pay \$13-\$15 per person immunized for the first 200 million people would provide a market comparable in size to the net present value (NPV) of revenues earned by the average of a sample of recently launched commercial products, adjusted for lower marketing costs. If sponsors wished to generate a similar level of competition as has been observed in vaccine markets in recent years, a price of $\$ 22-\$ 25$ would likely be more appropriate (depending on the disease). We use these benchmark commitment sizes along with estimates of the benefits of such a commitment (measured in terms of reduced disease burden) to estimate the cost-effectiveness of such commitments for the cases of malaria, tuberculosis, and HIV/AIDS. We show that under a reasonably conservative set of assumptions, a commitment of this size would be highly cost effective from a public health perspective for any of these diseases. For example, a malaria commitment of $\$ 15$ for the first 200,000,000 individuals immunized would cost less than \$15 per year of life saved; for tuberculosis a commitment of similar magnitude would cost \$31 per year of life saved; and for HIV/AIDS, \$17.

We also examine the more complex issue of the value of the commitment in accelerating the development and distribution of a vaccine, using malaria as an example, and find that even in the extreme case in which a commitment accelerated vaccine development by only one year and adoption in poor countries by only two years, a malaria commitment would cost about $\$ 80-\$ 90$ per additional year of life saved—still less than commonly-cited cost-effectiveness benchmarks for health interventions in poor countries.

\section{Brief background on advance market commitments}

As described in the Introduction, this paper focuses on two issues related to advance market commitments: first, what size of a commitment would provide a market comparable to those of existing biopharmaceuticals (Section 3); and second, how cost-effective would such 
commitments be under various contract models and assumptions (Sections 4 and 5). Other issues relevant to advance market commitments are discussed elsewhere; for example, Kremer and Glennerster (2004) discuss the rationale behind such commitments as well as design details, and Berndt and Hurvitz (2005) discuss some of the legal and economic practicalities of structuring advance market commitments.

In this section we describe the basic structure of advance market commitments, and then discuss one design issue of particular relevance for estimating the appropriate size of such commitments - namely, the treatment of second and subsequent market entrants.

\section{Basic structure of advance market commitments}

The basic structure of an advance market commitment is that sponsors commit (in advance of product development and licensure) to fully or partially finance purchases of vaccines for poor countries at a pre-specified price. A program sponsor or coalition of sponsors that potential investors in R\&D would find credible (i.e. sponsors that are financially solvent and thought to be unlikely to renege on a commitment) would sign a contract underwriting a guaranteed price for the vaccine supplier. Poor countries would decide whether to buy a given product at a low and affordable price (say, \$1 per treatment), and sponsors would guarantee to top-up to a higher price (say, \$15 per treatment) - thus providing market returns for the developer which are comparable to other average-revenue biopharmaceutical products. Once the full number of treatments has been purchased at the guaranteed price, the supplier would, in return, be committed to either selling further treatments at an affordable price in the long-term, or to licensing the technology to other manufacturers. Although not part of the contract, there would be nothing to stop the original sponsors or other donors from covering the $\$ 1$ price on behalf of poor countries at the time of purchase. 
For private firms, this type of advance market arrangement would reduce the political risk that firms would be forced to sell their product at a very low price, and thus would give investors confidence about the returns they could expect if the relevant scientific challenges were overcome. It is important to note that advance market commitments would not eliminate all risk to developers. In particular, the scientific challenges and associated risks (as in markets for diseases prevalent in rich countries) would be considerable, and the risk of failure high. But advance market commitments would greatly reduce the risks that are particular to markets for diseases concentrated in poor countries — especially the risk that once R\&D investments had been made, a company would face enormous pressure to sell the product at a very low price. In terms of $R \& D$ allocation decisions, advance market commitments would therefore put diseases like malaria or tuberculosis on a more equal footing with health conditions prevalent in affluent populations.

\section{Second and subsequent market entrants}

In calculating the commitment size necessary to put vaccines for diseases common in lowincome countries on an equal footing (in terms of research incentives) with products for diseases prevalent in rich countries, a key design question is how an advance market commitment would deal with second and subsequent market entrants. As discussed by Kremer and Glennerster (2004), advance market commitments can potentially be structured in a variety of ways to cover the case in which more than one vaccine is developed - ranging from, on one hand, giving no preference at all to the first vaccine (relative to later entrants) to, on the other hand, providing the entire reward to the developer of the first qualifying vaccine Appropriately balancing various considerations would require judgment calls on the part of sponsors about how they wanted to design the commitment, but it is worth briefly mentioning several relevant issues, both static and dynamic. 
From the perspective of static efficiency, if a superior product becomes available it should be used. From a dynamic standpoint rewards to individual developers should ideally reflect the marginal value of each vaccine to society; while it is difficult to precisely measure that marginal value, a system should aim to generate at least a rough correspondence between innovation incentives and the value of the innovation. Once a qualifying vaccine is developed, the incremental benefit of subsequent vaccines will typically be smaller, suggesting that in most cases it will typically be appropriate to provide smaller rewards for subsequent vaccines than for the initial vaccine, particularly if the subsequent vaccine is developed significantly later (in which case a large portion of R\&D expenditures for the subsequent entrant would have been incurred after the successful launch of the first product was clear). It is also worth noting that providing favorable treatment to subsequent products will tend to reduce incentives for the first developer, holding constant the total size of a commitment: to the extent funds are used for subsequent developers, they cannot be used to provide incentives for the first developer. Moreover, the provision of incentives for subsequent developers will likely also lead to reduced expected revenues for the first developer on commercial markets outside the advance market commitment. Overall, these considerations suggest that $R \& D$ on subsequent vaccines should only be rewarded if it leads to products with some superior characteristics.

Along these lines, the Center for Global Development report (Barder et al., 2005) recommends a mechanism similar to the "clinical superiority" clause embodied in the US Orphan Drug Act. The US Orphan Drug Act, which went into effect in 1983, created a number of financial incentives for biopharmaceutical companies to develop drugs for diseases such as Huntington’s, ALS (Lou Gehrig's disease), and muscular dystrophy - diseases which affect fewer than 200,000 people in the US and therefore have a limited market. The primary attraction for companies under this legislation was a promise of seven years of market exclusivity - unless a follow-on product 
was approved that was deemed to be "clinically superior.” The legal interpretations of this clause are beyond the scope of this paper, but in summary a product can be deemed clinically superior if it has shown greater effectiveness on a clinically meaningful endpoint - the demonstration of which most often requires direct comparative clinical trials. ${ }^{2}$ It is worth noting that the legal interpretations of this superiority clause (in particular, the "same vs. different" issue of whether two structurally similar drugs may be deemed “different” enough to justify multiple approvals for a given disease) have at times been controversial - for example, in the case of two drugs approved under the US Orphan Drug Act for human growth hormone (for legal analyses see Bohrer and Prince, 1999; Rin-Laures and Janofsky, 1991). ${ }^{3}$ We here do not focus on such issues, but note that they would need to be carefully crafted in the design of advance market contracts.

This superiority clause approach accomplishes a number of the goals we discussed above: first, it fashions incentives to appropriately reward development of the initial vaccine; second, it creates incentives to improve on the original vaccine; and third, it delivers the best available vaccines to patients.

To obtain a sense of how such a clause has worked in practice and how frequently clinically superior products have been approved, we examined the example of the US Orphan Drug Act. As of January 2006, approximately 280 drugs have been approved under the Act ${ }^{4}-$ only around three of which (two treatments for multiple sclerosis, one for coagulation factor IX) were allowed as second entrants to markets for which a previous drug had been approved under the US

\footnotetext{
${ }^{2}$ For more information on the regulatory structure of the US Orphan Drug Act, see the website of the US Food and Drug Administration (FDA)'s Office of Orphan Products (http://www.fda.gov/orphan/lawsregs.html, accessed 30 May 2006).

${ }^{3}$ Rin-Laures and Janovsky (1991) note the following regarding clinical superiority in the context of the US Orphan Drug Act: "A second drug is superior if it is (1) more effective, (2) safer, or (3) otherwise makes a major contribution to patient care, such as providing an oral form of the drug that is usually administered intravenously. This is an appropriate policy because it promotes research on safer or more effective versions of a drug that would otherwise be chilled by the presumption of 'sameness.'”
} 
Orphan Drug Act. ${ }^{5}$ These figures imply that over the entire period during which the US Orphan

Drug Act has been in place (that is, since 1983) only one percent of drugs that have been approved were approved as subsequent market entrants anytime over the time period. In the next section we examine how having such a clause in an advance market commitment would be taken into account in estimating the necessary size of a market commitment.

\section{Estimates of the appropriate size of a vaccine market commitment ${ }^{6}$}

Before delving into the details of various approaches to calculating market size, it is worth first noting that at least for vaccines that are currently in fairly early stages of development, and for which no single firm has a clear lead, larger commitment sizes will in expectation lead more firms to enter and more resources to be invested by each participating firm in the search for a vaccine. No single magic commitment size is the "correct" amount needed to incentivize research, below which no research will take place and above which further resources will be wasted. As in standard markets, many different biotechnology and pharmaceutical firms will make a series of decisions about which projects to pursue, how far to take them, whether to continue pursuing them in the face of setbacks, and which personnel to assign to the projects. These decisions will be influenced by the size of the commitment as well as by the number of competitors with whom a firm expects to potentially share revenue. At least to a first approximation, new firms will enter (and existing firms will invest more) until the net present value of investment for the marginal firm drops to zero. In expectation, increases in commitment size will be competed away through additional entry while more entry will on average increase the probability that a workable vaccine is developed and

\footnotetext{
${ }^{4}$ On drug approvals under the US Orphan Drug Act, see the website of the US Food and Drug Administration (FDA)'s Office of Orphan Products (http://www.fda.gov/orphan/designat/list.htm, accessed 30 May 2006).

${ }^{5}$ Information on subsequent market entrants approved under the "clinically superior" clause was obtained by a phone conversation with Peter Vaccari, RPh, RAC of the US Food and Drug Administration.
} 
increase the speed with which it is produced. Donors contemplating an increase in commitment size must trade off the risk of inefficient duplication of effort against the benefit of a shortened expected wait for a vaccine and the possibility of obtaining a better vaccine due to more entrants.

Rather than attempt to guess how much it would cost to develop a vaccine for a disease such as HIV, our strategy is therefore to ask how large a commitment would be needed to give developers incentives comparable to product markets for diseases prevalent in rich countries. To outline our approach as described in this section, we first estimate the net present value (NPV) of revenues earned by a sample of recently launched commercial pharmaceutical products. We then adjust this figure to account for the fact that developers of a vaccine under an advance market commitment would likely have lower marketing costs, and thus require somewhat lower revenues to generate the same incentive to invest in $\mathrm{R} \& \mathrm{D} .{ }^{7}$ We also adjust for the fact that the revenue from the commitment may potentially be shared between several successful developers (whereas our revenue figures are for individual products).

\section{Analysis of sales revenue data}

The most recent comprehensive evidence of sales revenues for biopharmaceutical products is a paper by Grabowski et al. (2002) in which the authors report on 118 new chemical entities (NCEs) that were introduced into the US pharmaceutical market between 1990 and $1994 .^{8}$ An important finding in the Grabowski et al. paper is that the revenue distribution over the sample set

\footnotetext{
${ }^{6}$ For details on the sales revenue data used in this section, see the Appendix. This data is also available upon request from the authors.

7 See Berndt et al. (2003)for other approaches and further discussion.

${ }^{8}$ Grabowski et al. (2002) note this is a comprehensive sample of the NCEs originating from and developed by the pharmaceutical industry that were introduced into the US in the 1990 to 1994 time period. Due to data limitations we are unable to address whether the sales revenues of this sample of self-originated NCEs is a representative sample of the sales revenues of all commercial pharmaceutical products. Sales revenue data from a larger sample of products is available from (for example) IMS Health or Scott Levin Associates, but is very expensive. Further work could attempt to pursue this and other potential sources of larger samples of sales revenue data.
} 
of products is not only widely distributed, but is also highly skewed..$^{9}$ In particular, in the

Grabowski et al. sample the top selling 10 percent of products earn approximately half of the total market revenues (in terms of worldwide sales). Using separate estimates of the cost of pharmaceutical development, Grabowski et al. also find that sales revenues of the median NCE are insufficient to break even, implying the mean sales revenue may provide a more reliable estimate of what level of expected revenues may be effective in spurring industry investment.

We obtained the sales revenue data compiled by Grabowski et al. (2002). The analysis presented in Grabowski et al. utilized this sales data in combination with estimates on the cost of pharmaceutical development in order to estimate total returns; we do not use those cost of development estimates nor any other cost of development estimates in our benchmark market size analysis. As discussed above, our strategy is to use sales revenue data alone to estimate the size of commitment needed to generate a market comparable in size to the sales revenues of products in the Grabowski et al. sample.

To transform the revenue stream into a net present value, we assume an estimated industrywide real cost of capital (that is, earnings foregone on other investment opportunities) of eight percent, close to the annual average return on the stock market (Siegal, 1998). ${ }^{10}$ This real rate of eight percent is equivalent to a nominal cost of capital of eleven percent, assuming three percent inflation. Using the sales revenue data together with this assumption of an eight percent real cost of capital, the NPV of revenues (pre-tax, and gross of plant, equipment, promotion and marketing,

\footnotetext{
${ }^{9}$ This finding is consistent with the findings of analogous earlier work on products introduced in the 1980s, such as that reported in Grabowski and Vernon (1990).

${ }^{10}$ Siegal (1998) estimates that the annual average return on the stock market over the time period from 19461998 was 7.8 percent (p. 318). We approximate this to eight percent for our analysis. We do not use the average return for pharmaceutical companies because - for a number of reasons - returns from an advance market commitment (which is public sector sponsored) would likely differ from returns in other private sector markets.
} 
production, and distribution costs) derived over the life cycle of the average product in the Grabowski et al. sample is $\$ 3.44$ billion (in 2004 dollars). ${ }^{11}$

The revenues reported by Grabowski et al. (2002) are partially spent on marketing. Since under a vaccine market commitment a potential vaccine manufacturer would likely need to spend considerably less than average on marketing, we take this into account and consequently adjust downward the above total revenue figure. Rosenthal et al. (2002) estimate that, relative to sales, expenditures on promotion by US pharmaceutical companies have remained fairly constant at about 15 percent of revenues, and have fallen slightly since $1998 .{ }^{12}$ It is plausible, however, that promotion/sales ratios are lower in Europe and elsewhere globally. In this sense the 15 percent number can be interpreted as an upper bound of what should be deducted from the overall market commitment size. Furthermore, in the US the 15 percent ratio is partly the result of an accounting nuance in which values of free samples given to physicians by drug representatives are assessed at average retail price, not manufacturer's production costs. For most drugs, relative to average retail price manufacturers' marginal drug production costs are quite low. Moreover, samples comprise about 50 percent of drug manufacturer's total promotional costs in the US (see Rosenthal et al., 2002). Given these considerations, reducing the commitment size by ten percent as a rough adjustment for promotional/marketing expenditures seems appropriate. After this adjustment, the

\footnotetext{
${ }^{11}$ The appropriate level at which to set the cost of capital is somewhat controversial. Grabowski et al. (2002) assume a real cost of capital of eleven percent, and previous analyses by two of the present authors (Kremer and Glennerster, 2004) used this assumption in calculating the NPV of revenues from existing commercial products. In this current work, our preferred estimates use an assumed eight percent real cost of capital for two reasons. First, eight percent is close to the annual average return on the stock market (Siegal, 1998). Second, this allows for consistency in our analysis between estimating the NPV of revenues of existing products and estimating the NPV of revenues under a vaccine market commitment. With an eleven percent real cost of capital, the NPV of revenues for the average product would be $\$ 2.81$ billion rather than $\$ 3.44$ billion.

${ }^{12}$ It is worth noting some argue that in fact marketing and related promotion expenditures are a much higher percent of revenues; Angell (2004), for example, argues they may be as high as 36 percent of revenues. While precise measurement of this ratio is inherently difficult (and controversial, given difficulties in allocating some educational and $\mathrm{R} \& \mathrm{D}$ activities as partly promotional), we note that the larger percentages, such as those cited by Angell, typically refer to total selling and general administrative (S\&GA) expenses.
} 
program would need to pay out $\$ 3.1$ billion to match the average revenue brought in by existing NCEs.

Although it is difficult to formalize into a rigorous analysis, a useful benchmarking exercise for our market size estimate is provided by the rules of thumb venture capitalists and pharmaceutical analysts say they use in thinking about new potential products. These opinions can arguably serve as one rough check on our estimates as derived above. A common perception among analysts and potential developers (as well as many in industry) is that large biopharmaceutical companies need to anticipate annual sales of $\$ 500$ million or more in years with peak sales in order to be willing to invest in R\&D for a new product (see Robbins-Roth, 2000). Assuming the typical product life cycle as in Grabowski et al. (2002) and a real cost of capital of eight percent, after adjusting down by ten percent for lower marketing costs this rule-of-thumb corresponds to an NPV of about $\$ 3.38$ billion, a number fairly close to that which our procedure yields. $^{13}$

\section{Potential market size adjustments}

While revenues for existing products arguably give us a good sense of the market size sufficient to generate the development of new products, there are several ways in which an advance market commitment differs from a standard market, and in calculating the appropriate commitment size sponsors may wish to adjust for some of these differences. In this sub-section we discuss several potential adjustments - such as that some vaccines may have received substantial direct public or philanthropic support, and the risk that a developer might have to share the market with another product. Wherever possible we draw on the historical record in order to estimate how large

These S\&GA expenditures include non-marketing related general administration, and therefore likely overstate total marketing and related promotion expenditures.

${ }^{13}$ With an 11 percent real cost of capital (as in Grabowski et al., 2002), this figure changes from $\$ 3.38$ billion to $\$ 2.76$ billion. 
an adjustment would be necessary to reflect these differences between an advance market commitment and a standard market.

While many biopharmaceutical products included in the Grabowski et al. (2002) data have benefited from public and nonprofit investment in $R \& D$ in their development, certain diseases that are likely to be the focus of advance market commitments may arguably have attracted more than average attention from governmental and philanthropic sponsors. Research into a malaria vaccine, for example, has received significant financial support from the Malaria Vaccine Initiative, which in turn is supported by the Bill \& Melinda Gates Foundation. Because this direct funding offsets some of the costs of development, the appropriate commitment size would be smaller. The magnitude of this adjustment would differ across diseases. A commitment could also potentially be designed so as to explicitly adjust the reward based on the amount of direct funding that had been received from various donors prior to the announcement of the advance market commitment. (Subsequent funders could presumably work out - directly, with developers - arrangements they felt were appropriate.)

Similarly, the commitment size should take into account how far along in the development pipeline a vaccine is - namely, the more developed a vaccine is, the lower the appropriate commitment size relative to our revenue-based estimates. Again, this adjustment would be calculated on a disease-by-disease basis. For products such as a rotavirus vaccine which are in very advanced stages of development, the necessary size of a commitment could be much smaller; for intermediate stage products such as a malaria vaccine (where, as we discuss in Section 4, there are already candidate vaccines) the size of a commitment may need to be adjusted downward; and for very early-stage vaccines such as for HIV or tuberculosis the benchmark market size estimates we discuss here may be appropriate. 
On the other hand, the revenue data we use (by its nature) covers existing products and thus includes the "low-hanging fruit" of products that were relatively easier to develop. To the extent that there is a general consensus that developing (for example) an HIV vaccine is more technologically challenging than developing the typical product, the appropriate commitment size would be greater. As no one knows how much it will cost to develop these vaccines, any adjustment of this kind would necessarily involve considerable judgment calls.

The Center for Global Development Working Group (Barder et al., 2005) recommended setting a commitment comparable in size to the net present value of revenues for an average new chemical entity. If the value of the market were set at this level, firms would be willing to enter (assuming technological opportunities were similar to those for typical developed country products) but would not be willing to accept a high risk of having to share the market, or a high risk of being beaten to the market by another vaccine. Thus, in equilibrium we would expect entry, but at a lower level than in average, standard markets.

If sponsors wish to create incentives designed to generate the typical level of competition in the vaccine market, a larger commitment would be needed. The more likely a commitment is to be split between different products (i.e. the more subsequent entrants there are likely to be) the larger the commitment needed to generate the same incentive for investing in $R \& D$ to develop a vaccine.

If sponsors wish to spur enough entry that multiple products are likely to be developed, it may be appropriate to set the commitment size such that a successful vaccine developer could anticipate receiving revenue similar to that in the Grabowski et al. (2002) revenue data even with substantial competition and sharing of the market.

The commitment size necessary to encourage a particular amount of entry (with the goal of either advancing the date a vaccine is developed or leading to the development of superior 
vaccines) depends on the rules of the commitment regarding subsequent developers. One problem is that in the absence of a superiority clause, a larger commitment size could potentially lead to entry of firms aiming for an earlier vaccine or a better vaccine, but it could also lead to entry of firms seeking merely to produce a "me too" product so as to obtain revenue that would otherwise go to competitors. As discussed in Section 2, our benchmark assumption is based on the Center for Global Development proposal (Barder et al., 2005), under which a commitment would allow competition from subsequent entrants, but only if qualifying under a clinical superiority clause (for at least some populations). Including a clinical superiority clause would accomplish the goals of appropriately rewarding development of the initial vaccine, creating incentives to improve on the original vaccine, and delivering the best available vaccines to patients. From the perspective of a developer who perceives having a substantial chance either of being first or being superior, a superiority clause has the advantage of reducing the likelihood of having to share the market with a subsequent non-superior entrant. Under a commitment with a superiority clause a developer who is far behind in a race and does not anticipate their product being superior for at least some populations will drop out of the race. This is socially efficient because there is little value to society of having a second vaccine that is no better than the first.

To illustrate, suppose that sponsors wanted to generate sufficient entry such that each potential developer would expect that if they succeed in developing a qualifying product, they would be competing with one other qualifying product - either by sharing the market or by engaging in a race to produce a licensed qualifying product with another firm that would ultimately produce such a product. Suppose also that sponsors wanted to provide each firm with an amount of revenue comparable to that obtained by the typical new chemical entity. In that case, it would be necessary to apply an adjustment factor of two - thus offering twice the amount discussed above, or slightly more than $\$ 6$ billion. 
Sponsors might reasonably wish to offer each successful developer expected revenues similar to our \$3.1 billion benchmark while also encouraging a similar degree of entry as currently found in other vaccine markets. Below we examine the number and timing of entrants in the markets for nine recently developed vaccines (hepatitis A, hepatitis B, haemophilus influenzae type b [Hib], meningococcal, pneumococcal, varicella, rubella, measles and mumps). ${ }^{14}$ We calculate how many vaccines were developed for a given disease within a six year window of the first entrant being licensed, and how many of these subsequent entrants would likely have been considered superior to the initial entrant. This allows us to examine the cost of inducing a certain amount of entry of "high social utility" products (i.e. the original entrant in addition to superior products) depending on the amount of revenue committed and the rules of the program.

In our data, on average 2.3 vaccines were developed for each disease in the six year window after approval of the first vaccine (or 2.6 if we use data from pre-1980, which is arguably inappropriate given that in the 1960s and 1970s the vaccine industry was much less consolidated than it is today). We use a somewhat arbitrary cut off of six years for two reasons. First, under an advance market commitment the original developer need not worry about sharing the market with a vaccine which will be approved six years later because the commitment will likely be exhausted by that time; second, being six years behind in such a race would arguably deter subsequent developers from undertaking heavy investments. Because a large proportion of development expenditure occurs in the final few years before a vaccine is approved, a similar argument holds (to a lesser degree) for years two through six as well. ${ }^{15}$

\footnotetext{
${ }^{14}$ We collected data from a number of sources (primarily historical documents from the US Centers for Disease Control and US Food and Drug Administration) on vaccine approvals and characteristics (efficacy, number of doses, etc.) that could be used to determine whether a given non-initial entrant would likely have been considered superior. Documentation of our data and assumptions is available upon request from the authors.

${ }^{15}$ For example, survey data suggests that Phase III clinical trials represent approximately two-thirds of the costs of development (DiMasi et al., 2003).
} 
For example, it seems likely that if a superiority clause is in place, a developer may be unlikely to proceed with phase III trials if a vaccine has already been approved under an advance market commitment and the developer does not believe its vaccine will qualify under a superiority clause. This represents an efficiency gain and also means the commitment size need not be adjusted upwards (because donors have no interest in stimulating another vaccine that is no better than the first). In calculating our adjustment factor we therefore place a lower weight on entrants who enter two to six years after the initial approval. ${ }^{16}$ Taking into account this weighting for products which would likely have been considered non-superior, the average number of (weighted) entrants is 1.69 using data since the 1980s (or 2.14 including data from the 1960s and 1970s). In other words the commitment size would have to be 69 (or, respectively, 114) percent larger in order to provide revenues similar to that from the typical new chemical entity for each product while also generating a level of competition historically associated with the vaccine industry.

This calculation is also instructive is estimating the value of the superiority clause. Without a superiority clause it would be necessary to compensate initial developers more for the risk of sharing the market with a second, possibly non-superior entrant. Based on our data as described above, without a superiority clause the adjustment factor would need to be 2.33 (using data from the 1980s forward), relative to our 1.69 estimate with a superiority clause. On the base of a benchmark \$3.1 billion NPV revenues per product, this translates into a commitment size of $\$ 5.24$ billion with a superiority clause and $\$ 7.22$ billion without a superiority clause-implying that the superiority clause may save donors $\$ 1.98$ billion while creating the same incentive to develop the first vaccine or vaccines judged likely to be superior.

\footnotetext{
${ }^{16}$ Specifically, a weight of 0.25 is applied to non-superior products entering between two and six years after the initial entrant. This assumption was informed by estimates of the percentage of expenses spent on various phases of clinical trials as well as the assumption that entrants less than two years out would likely not abandon their late phase II and phase III trials which together are estimated to represent approximately three-fourths of the costs of development (DiMasi et al., 2003).
} 
On a separate point, it is also worth noting that if donors wish to encourage subsequent market entrants (for example, to obtain a vaccine with a higher rate of efficacy), it would be possible to add additional market commitments (for the same disease) at a later date with this goal specifically in mind. Since we estimate that the bulk of the NPV of revenue associated with a successful product under an advance market commitment comes within the first three to five years, it is unlikely that the possibility of such subsequent commitments would substantially affect the calculations.

In Table 1, we report the necessary NPVs of sales that would make the total market for a desired vaccine comparable to that of five different representative products from the Grabowski et al. (2002) sample, corresponding to the averages of the five upper deciles of the sales distribution. ${ }^{17}$ (Specifically, in the first decile, the reported number represents the average among the top selling 10 percent of NCEs. For the second decile, it is the average of the next 10 percent, etc.).

The average product lies in the fourth decile of sales, and it can be seen in the table that the top two deciles of the distribution generate the largest portions of sales revenues. Therefore, if the development of a vaccine were considered of very high social value it might be seen as appropriate to attempt to create an incentive that matched some of the best selling drugs for rich country diseases as a way to generate the multiple large scale research projects we observe for (for example) diseases such as hypertension or cancer. The size of the commitment needed to match these markets would need to be substantially increased given the skewed distribution of revenues seen in the data. ${ }^{18}$

\footnotetext{
${ }^{17}$ Figures for the $1^{\text {st }}$ decile, $2^{\text {nd }}$ decile, and average product are taken directly from Grabowski et al.'s data. Deriving the 3rd, 4th, and 5th decile figures required slight approximation due to data limitations. Details on these calculations are available from the authors.

${ }^{18}$ It is noteworthy that very few of the products in the Grabowski et al. (2002) sample are likely to be vaccines. Among existing vaccines, the hepatitis $\mathrm{B}$ vaccine may provide the best comparison to our hypothetical malaria vaccine, as it is a relatively new antigen that has seen a widespread increase in demand during the last decade. As evidence of a demand-induced R\&D activity, Finkelstein (2004) reports an increase in $\mathrm{R} \& \mathrm{D}$ investment on hepatitis B vaccines in response to the Advisory Committee on Immunization
} 
To summarize our work in this section, an estimate of the net present value of revenues that a vaccine advance market commitment would need to offer in order to match existing commercial products would be $\$ 3.1$ billion, in year 2004 dollars. Because the starting year of purchases under the program is highly uncertain, the commitment should be indexed to account for inflation; here we express all monetary values in 2004 dollars. In this section we also discussed various reasons why donors may wish to adjust this benchmark figure upwards (for example, because of potential subsequent, superior market entrants) or downwards (for example, because of more directly-financed $R \& D$ than for a typical disease prevalent in developed countries); for the remainder of this paper we focus on the benchmark \$3.1 billion figure, but as we discuss in Section 4 readers can make calculations with adjusted figures using our web-based spreadsheet tool.

\section{Cost effectiveness of a vaccine advance market commitment}

We now consider the net present value of revenue and health cost-effectiveness estimates that would be generated by a vaccine advance market commitment for three specific diseases (malaria, tuberculosis, and HIV/AIDS) under various scenarios. These estimates have been generated by a spreadsheet tool (available online at http://post.economics.harvard.edu/faculty/kremer/vaccine.html) that allows the user to manipulate all relevant variables in a flexible way, thereby permitting the generation and analysis of a large number of different scenarios.

In the discussion below we provide details on the case of malaria as an illustration of the type of calculations and assumptions that are necessary for this work. In Section 5, we also focus

Practice (ACIP) recommendation in 1991 to give hepatitis B immunization to US infants. Immunization rates strongly increased thereafter, to almost 90 percent, and a significant number of additional clinical trials were conducted. The worldwide market for hepatitis B vaccines currently lies at around $\$ 1$ billion annually, which makes the set of all hepatitis B vaccines comparable in market size to a single product with a NPV of sales (assuming an eight percent real cost of capital) of approximately $\$ 6.49$ billion. Details of this calculation are available from the authors. 
on the example of malaria in illustrating to which parameters the cost effectiveness results are and are not sensitive. We chose to focus on malaria since it is a disease for which it is relatively more straightforward to make assumptions about who would be vaccinated and how, because (as we discuss below) there are natural existing delivery systems through which to reach the two target risk groups (namely, children under the age of five and woman pregnant for the first time). In contrast, for diseases such as HIV and tuberculosis there are complex questions about who should be vaccinated that are beyond the scope of this paper. However, as we make clear below, most of the general conclusions below apply to vaccines for any of the three diseases.

To obtain concrete cost effectiveness numbers we also need to consider a particular set of contract provisions and vaccine characteristics including assumptions about which countries would participate in the program, vaccine adoption rates, and sources of additional revenue to the vaccine supplier (e.g. travelers’ or military purchases). These parameters and assumptions can be modified in the spreadsheet, thus allowing the user to investigate the impact of alternative contract parameters and different assumptions regarding take-up, disease burden, etc. For example, the spreadsheet allows the user to assess the revenue and cost-effectiveness consequences of different combinations of price, quantity, and vaccine characteristics. Based on the user inputs as well as recent data compiled on disease burden and population, the spreadsheet outputs the cost per disability adjusted life year (DALY) saved by the program and the NPV of revenues that would accrue to the vaccine supplier. ${ }^{19}$

Since the values of revenues and cost per DALY saved are expressed in real terms at the time the vaccine is developed, even though altering the years until a vaccine is developed will change the nominal price paid, it will not alter the results of the calculations presented here.

\footnotetext{
${ }^{19}$ Disability adjusted life years, or DALYs, are a commonly used metric which attempt to account for both life lost due to premature death and the loss of healthy life resulting from disease morbidity or disability.
} 
The calculations presented in this section are intended to demonstrate that, once a vaccine is developed, purchasing vaccine at the pre-specified price would be a very cost-effective expenditure. In Section 5 we examine cost-effectiveness in the context of a somewhat more complex issue - namely, the value of the commitment in accelerating the development and distribution of a vaccine.

As a benchmark for cost-effectiveness comparisons, we note that health interventions in the poorest countries are generally regarded as highly cost effective if they cost less than $\$ 100$ per DALY saved (World Bank, 1993). ${ }^{20}$ More recently a country’s gross national product (GNP) per capita has also been used as a benchmark (GAVI, 2004; WHO, 2000a) and in the United States, the cost-effectiveness threshold is estimated to be as high as $\$ 50,000$ to $\$ 100,000$ per DALY saved (Neumann et al., 2000). As an alternative benchmark, even at the lowest of recently negotiated estimates of prices for antiretroviral drug treatments for HIV, the cost of purchasing and delivering antiretrovirals using a directly observed treatment short-course (DOTS) is estimated to cost $\$ 613$ per year of treatment. ${ }^{21}$

To summarize our results, we find that under a reasonably conservative set of assumptions, a commitment to pay $\$ 15$ per person immunized for a malaria vaccine (or \$5 per dose for a threedose vaccine) for the first 200 million people immunized (as recommended by the Center for Global Development report [Barder et al., 2005]) would cost less than \$15 per DALY saved, including both purchase and delivery costs of the vaccine. Sales under the program would provide about $\$ 3.2$ billion in total NPV of revenues to the vaccine developer, comparable to the $\$ 3.1$ billion

\footnotetext{
${ }^{20}$ In 2004 dollars, this would be approximately $\$ 128$.

${ }^{21}$ Although estimates of the cost of antiretroviral treatment per year of life saved are sensitive to assumptions about the cost of delivery and the epidemiological effects of treatment (which could be either positive or negative, depending on behavioral response), the 2001 call by 133 Harvard faculty members for antiretroviral treatment (Adams et al., 2001) estimated that purchasing and delivering antiretrovirals using a DOTS approach would cost $\$ 1,100$ per year. That analysis assumes an average cost of $\$ 650$ per patient per year for costs of antiretrovirals. Adjusting that analysis for the lowest of the recently negotiated estimates of
} 
in total NPV of revenues of the average product as discussed in Section 3. If sponsors wanted to generate more competition, compensate developers for the risk that they might have to share the market and increase the likelihood of a vaccine being developed more quickly, they could offer a price of \$28 per person immunized for the first 200,000,000 people immunized. Even in the absence of potentially moving forward the date of vaccine development, this would generate a market of $\$ 5.2$ billion and cost less than $\$ 21$ per DALY saved. This result is derived from baseline assumptions which are detailed below for the case of malaria.

Although we here do not focus on the details of our calculations for tuberculosis and HIV/AIDS (these assumptions are described in detail in the spreadsheet tool), it is worth briefly summarizing our main results for these diseases. For tuberculosis, under conservative assumptions similar to those for malaria and a similar contract design, our simulations suggest that a commitment to purchase a tuberculosis vaccine at \$13 per person immunized for the first 200 million people immunized would cost \$31 per DALY saved and would generate \$3.3 billion in total NPV of revenues to the vaccine developer. ${ }^{22}$ For the case allowing subsequent entrants under a superiority clause, the analogous figures are a slightly higher but still modest cost per DALY saved (less than $\$ 44$ ) and $\$ 5.2$ billion in total NPV of revenues to the vaccine developers.

For HIV/AIDS, again using conservative assumptions and a similar contract (namely, \$14 per person immunized for the first 200 million people immunized), our simulations suggest that a commitment to purchase an HIV vaccine would cost less than \$17 per DALY saved and would generate about $\$ 3.3$ billion in total NPV of revenues to the vaccine developer. ${ }^{23}$ For the case

antiretroviral costs, \$140 per year (McNeil, 2004), suggests a cost per year of treatment of approximately $\$ 613$.

${ }^{22}$ Our simulated tuberculosis vaccine would protect with $60 \%$ efficacy for 20 years, and would be adopted at rates consistent with current DPT3 rates among infants and a rate of $30 \%$ by older cohorts.

${ }^{23}$ Several important departures from the assumptions described below for the malaria vaccine simulation are that we assume that the HIV vaccine would be delivered to school-age children at a cost of \$2 per dose; that adults would adopt the vaccine at a rate of $30 \%$ in countries in which the vaccine becomes available under the program; and the vaccine would protect with $60 \%$ efficacy for 20 years. 
allowing subsequent entrants under a superiority clause, the analogous figures are \$21 per DALY saved and $\$ 5.2$ billion in total NPV of revenues to the vaccine developers. Sensitivity analyses for the malaria case are presented in Section 5, but we note that sensitivity analyses for the HIV/AIDS and tuberculosis cases produce similar results.

\section{Case study: Malaria}

The World Health Organization (WHO) estimates that more than 300 million people contract clinical malaria every year, and that 1.1 million annually die of the disease (WHO, 2001). Children who survive severe cases of malaria may suffer learning disorders and brain damage, although those who reach age five acquire some immunity. Those with this limited natural immunity rarely die from malaria, but often later in life they become weak and lethargic with the disease, thus experiencing losses in welfare and productivity. Almost all malaria cases occur in low-income countries, and about 90 percent of the victims live in sub-Saharan Africa (WHO, 2000b).

The scientific challenges in developing an effective malaria vaccine are formidable, but in recent years several candidate malaria vaccines have progressed to phase II clinical trials including at least three being studied in target (pediatric) populations in field settings (Ballou et al., 2004). For example, a candidate vaccine from GlaxoSmithKline Biologicals (with support from the Malaria Vaccine Initiative, the Bill \& Melinda Gates Foundation, and the Mozambique Ministry of Health) recently completed phase IIb trials, where the vaccine’s efficacy against severe malaria disease was found to be 58 percent (Alonso et al., 2004). Two other candidate vaccines currently being tested in pediatric populations include a vaccine candidate being led by the Walter Reed Army Institute of Research (WRAIR), with support from the US Agency for International Development (USAID), GlaxoSmithKline Biologicals, and Statistics Collaborative Inc.; as well as 
a vaccine candidate being assessed by the University of Oxford, with support from the Gates Malaria Partnership at the London School of Hygiene and Tropical Medicine, and the Wellcome Trust. $^{24}$

Many steps remain before these or other candidate malaria vaccines would be ready for widespread use. Vaccine advance market commitments can provide financial incentives to pull these candidate vaccines through costly phase III clinical trials and other steps required for licensure, towards final delivery.

As discussed in Section 2, the appropriate size of an advance market commitment would vary by disease depending on a number of factors, including how much R\&D on candidate products is being funded through directly-financed mechanisms. For the case of malaria, obviously it is impossible to predict whether the leading GlaxoSmithKline candidate vaccine will be successful in clinical trials. If the GlaxoSmithKline candidate vaccine is successful, a market size commitment smaller than our benchmark size of $\$ 3.1$ billion would likely be appropriate in light of extensive directly financed R\&D. On the other hand, in the case in which this GlaxoSmithKline candidate vaccine is not successful, donors may wish to have an advance market commitment in place to encourage the development of other candidate products - and in that case, the benchmark commitment size of $\$ 3.1$ billion may be appropriate. Such a commitment could be put in place either now or after the realization of (for example) Phase III outcomes on the GlaxoSmithKline candidate vaccine. Such design issues are beyond the scope of this paper, so here we simply analyze the case in which the GlaxoSmithKline candidate vaccine is not successful, for which the benchmark \$3.1 billion commitment size may be appropriate.

\footnotetext{
${ }^{24}$ For details on these and other candidate malaria vaccines, see Ballou et al. (2004), the World Health Organization's website (http://www.who.int/vaccine_research/documents/en/malaria table.pdf, accessed 30 May 2006), and the Malaria Vaccine Initiative (MVI) website (http://www.malariavaccine.org/abcurrent_projects.htm, accessed 30 May 2006).
} 


\section{Contract provisions}

We consider a commitment that would offer an initial price of \$15 per person (in 2004 dollars) for the first 200 million people immunized, after which the price would drop to \$1 per person immunized.

Following the public health literature, we apply a default annual discount rate of three percent to future DALYs saved and future expenses to the program sponsor. Firms, however, may discount future revenues at a higher rate reflecting the cost of capital. We consider a real rate of eight percent, close to the annual average return on the stock market (Siegal, 1998).

\section{Vaccine characteristics}

In our base case, we consider a three-dose, 60 percent effective vaccine that would protect for five years and could be added to the standard package of vaccines that are delivered under the WHO’s Expanded Programme on Immunization (EPI). That package, which includes three contacts with each child, costs $\$ 15$, or $\$ 5$ for every contact (World Bank, 1993). The majority of this cost is due to delivery costs, as the price of the six traditional EPI vaccines is very low. The World Bank estimated that adding the one-dose yellow fever vaccine and the fairly expensive three-dose hepatitis B vaccine to the EPI package would increase the cost of the package by 15 percent, or \$2.25, including both the purchase price and the delivery cost (World Bank, 1993). Both yellow fever and hepatitis B were expensive vaccines, so we assume that the incremental cost of adding a three-dose vaccine to the EPI package would be no more than $\$ 0.75$. However, as discussed in the sensitivity analysis below, even at several multiples of this cost, delivery would still be quite inexpensive. (Note that in the spreadsheet tool, extra delivery costs can be specified for vaccines that are not compatible with the EPI schedule, but in the base case for malaria discussed here we consider vaccines that are in conformity with the EPI schedule.) 
Vaccine efficacy reflects the percentage of infections that are prevented by immunization, and defaults to 60 percent. The duration of protection reflects the number of years after immunization that the vaccine protects against infection, and defaults to five years.

\section{Countries covered}

An important set of assumptions concerns the countries that will participate in the program, i.e. the populations for which the vaccine doses will be purchased. This selection has a considerable impact on the effectiveness of the program, because the burden of malaria and vaccine adoptions rates differ widely across countries. In the spreadsheet tool, we allow selection by several different criteria, including a gross national income (GNI) per capita cutoff ( $\$ 1000$, the cutoff currently used by the Vaccine Fund ${ }^{25}$, is the default), a 'manual' selection of countries, and a minimum disease prevalence cutoff. In the baseline case presented here we use the $\$ 1000$ GNI per capita cutoff to define eligibility, and from there assume that eligible countries will participate if vaccination is cost-effective (i.e. less than $\$ 100$ per DALY saved) at delivery cost in that country. That is, we assume that countries in which vaccination would not be cost-effective at delivery cost would not participate in the program. In addition, China is not included in the program because its GNI will soon surpass the $\$ 1000$ cutoff, and because falciparum malaria, the most deadly form of malaria, is only a problem for a tiny fraction (less than 1 percent) of China's population.

\section{Adoption}

Obtaining cost-effectiveness estimates for a vaccine requires us to make additional assumptions about the adoption patterns for the vaccine. Because there is little historical data to

\footnotetext{
${ }^{25}$ The Vaccine Fund is the financing arm to the Global Alliance for Vaccines and Immunization (GAVI). The Vaccine Fund offers support to qualifying governments of the world's poorest countries for: (1) new and under-used vaccines; (2) funding to help governments strengthen their basic immunization services; and (3)
} 
guide assumptions, in general we make conservative assumptions about take-up rates. In addition, the robustness checks we will present in Section 5 suggest our estimates are relatively insensitive to assumptions about adoption.

Adoption of the vaccine will likely gradually increase over several years and eventually reach a steady-state level. In our base case scenario we consider a linearly increasing take-up path that takes seven years to reach the steady state. In this base case, the uptake rates for new cohorts (infants) are set to the country-by-country immunization rates for the diphtheria-pertussis-tetanus three-dose vaccine (DPT3) reported by the WHO (2002), plus five percentage points. This assumes that the immunization rates would be at least as high as the current DPT3 rates if the vaccine could be added to the EPI schedule. We argue it is appropriate to assume the addition of five percentage points to the current DPT3 rates for several reasons, including the likely increase in immunization rates that will result from the recent influx of financial support for immunizations (for example, from the Bill \& Melinda Gates Foundation), economic development that will likely increase immunization rates (for example, due to increased urbanization), and immunization rates that may be higher if parents value immunization more if a malaria vaccine were available. The spreadsheet also allows the user to base uptake rates on diphtheria-pertussis-tetanus first-dose (DPT1) or measles coverage rates, or to specify a single rate for all countries.

In the transition years of the program, there may be backlog immunizations of children who have not yet acquired natural immunity to the disease. Given that expanding the program beyond those relatively easy to reach will be difficult, we assume that only a minority of this population will be reached. Specifically, we assume that 10 percent of the children aged 0-4 will be immunized.

safe injection equipment in the form of auto-disable syringes and safe disposal boxes. More information is available online at http://www.vaccinealliance.org (accessed 30 May 2006). 
Women temporarily lose their natural immunity to malaria during their first pregnancy, and thus we include some immunizations of pregnant women. The number of pregnant women who are in their first pregnancy and thus need to be vaccinated is approximated by taking one fourth of annual births. ${ }^{26}$ The default immunization rate for this population is set to the tetanus toxoid (TT2) rate reported by the WHO (2002) plus five percentage points (for reasons described above). The tetanus toxoid vaccine is already given to pregnant women and thus can serve as a proxy for the access to and demand for vaccinations in that subpopulation.

\section{Additional revenues}

The vaccine developer would also receive revenue outside of program purchases, such as private purchases in covered countries and purchases in non-covered countries (such as the travelers' and military markets in high-income countries, as well as middle-income countries where malaria is prevalent).

In the base case we project a total market of $\$ 750$ million in NPV of revenues (2004 dollars) in high- and middle-income countries. This estimate is based on annual purchases of malaria prophylaxis drugs, as presumably people would be willing to pay comparable amounts for a malaria vaccine as for malaria prophylaxis drugs. An estimate from the popular press (Reuters, 2003) and correspondence with Pfizer suggest that the annual market for malaria prophylaxis drugs from sales to travelers and tourists from industrialized countries and the military could be as much as \$200 million, but others cite much lower figures. If a vaccine captured \$100 million in peak sales and the profile of sales over time followed that of a typical pharmaceutical in the Grabowski et al. (2002) sample, the total net present value of those sales would be about $\$ 750.7$ million. ${ }^{27}$

\footnotetext{
${ }^{26}$ The average fertility rate (births per woman) in low-income countries in 2002 was four (World Bank, 2005), hence our assumption of one-fourth of total births being first pregnancies.

${ }^{27}$ With an 11 percent real cost of capital (as in Grabowski et al., 2002), this figure changes from $\$ 750.7$ million to $\$ 613.9$ million. Note that for both of these figures, we have not subtracted out 10 percent for
} 
Adding in \$100 million of additional revenues from private sales in low- and middle-income countries yields a default of $\$ 850$ million in net present value of revenues outside the commitment program.

\section{Baseline results}

Given the assumptions outlined above, along with a recent collection of data from the World Health Organization (1997) and the US Bureau of the Census (2002) on disease burden and fertility, as well as estimates of the distribution of the burden of disease by age and gender, the spreadsheet tool projects the total discounted number of DALYs that would be saved by the program. It also calculates the total cost, including delivery costs, and the revenues to the vaccine supplier from purchases at the initial (high) price. The purchases at the subsequent lower price are ignored for the NPV calculations because the low price would presumably be close to the marginal cost of production and because for later sales it is increasingly less likely that the supplier would remain the same.

We then calculate the expected number of DALYs that would be saved by the program each year by multiplying the number of immunizations by vaccine efficacy and by the DALY burden of disease faced by members of the population immunized over their lifetime or the lifetime of the vaccine. The cost of the program in each year is calculated as the number of vaccinations multiplied by the total cost of each vaccination (purchase price and delivery cost). As discussed above, we follow the public health literature and discount both future DALYs saved and future expenditures to the program sponsor at a real discount rate of three percent. The total discounted revenue to the supplier in each year is calculated as the number of purchases at the initial price multiplied by the initial price, discounted at the real cost of capital of eight percent. In order to 
evaluate the appropriateness of the size of the price commitment, one can then compare the NPV of revenues from a new vaccine to the adjusted distribution of revenues from a sample of existing commercial products, as detailed in Section 3.

These calculations may underestimate the cost-effectiveness of the vaccine. For example, these calculations do not include any epidemiological "herd" benefits—-that is, vaccinating a significant fraction of the population may slow the spread of a disease, and thus benefits may spill over to the unvaccinated. They also do not include health benefits to people in middle- and highincome countries, or benefits to adults in low-income countries who purchase a vaccine privately. They assume that the vaccine would be given randomly throughout a country and thus do not factor in any benefits of targeting vaccine delivery within countries to areas that have the most severe disease problems. Finally, these calculations do not include the benefits of increasing vaccination rates for other diseases that might result from parents bringing their children into clinics to vaccinate them against malaria.

For a given set of specified assumptions, the main outputs of the spreadsheet tool are the total NPV of revenues that would accrue to the vaccine supplier and the cost per DALY of the vaccine, both in 2004 dollars. Under the base case assumptions described above, a commitment to pay \$15 per person immunized for the first 200 million individuals immunized would produce a total NPV of revenue of $\$ 3.2$ billion (in 2004 dollars), comparable to the $\$ 3.1$ billion benchmark for the average existing NCE as discussed in Section 3.

The spreadsheet tool also reports the annual number of vaccinations in the steady state, the annual number of DALYs saved in the steady state, and the overall cost per DALY saved. Under the baseline assumptions, over 54 million people would be immunized annually, saving almost 14 million DALYs per year in the steady state. Overall, the program would cost less than $\$ 15$ per 
DALY saved, which is highly cost effective relative to, for example, the $\$ 100$ per DALY costeffectiveness standard.

\section{Sensitivity analyses}

In this section, we discuss the cost-effectiveness of a vaccine market commitment program when the base case assumptions are varied. The sensitivity analyses reported below also highlight the key aspects of a vaccine that make it cost effective and that therefore should be carefully considered in the choice of eligibility criteria for a product to be purchased under the program.

The cost-effectiveness of the vaccine is relatively insensitive to changes in assumptions about efficacy, take-up rates, and the per immunized-person price offered. For example, a malaria vaccine that was only 50 percent effective would still cost less than $\$ 20$ per DALY. Figure 1 shows the relationship between efficacy and cost per DALY, holding constant all other inputs, including the set of countries participating in the program. Even a 30 percent effective vaccine would be highly cost-effective.

If adoption of the vaccine is very slow, the program would still remain very cost-effective from a public health perspective and would still provide a considerable amount of revenue to the vaccine developer - although somewhat less revenue than in the case of a more rapidly adopted vaccine, since under this type of contract the value of payments for the high-price vaccine doses declines as a result of discounting when these vaccinations are pushed further into the future. If it takes fifteen years for adoption to reach steady-state levels and adoption only reached levels 10 percentage points below the DPT3 rates, the program would still cost less than \$20 per DALY saved and would generate $\$ 2.7$ billion in NPV of revenue for biopharmaceutical companies (in 2004 dollars). 
A vaccine commitment would also be cost-effective at the time of vaccine development under a wide range of contract provisions. For example, to match the revenues of drugs falling between the $70^{\text {th }}$ and $80^{\text {th }}$ percentile and generating a market roughly comparable to $\$ 3.61$ billion in net present value of sales, a commitment could offer \$17 per person immunized for the first 200 million people immunized, at a cost of about \$16 per DALY saved. To match the revenues of drugs falling between the $80^{\text {th }}$ and $90^{\text {th }}$ percentile and generating a market roughly comparable to $\$ 5.73$ billion in net present value of sales, a commitment could offer \$25 per person immunized for the first 250 million people immunized, at a cost of about \$23 per DALY saved. As discussed below, if raising the price offered per person immunized accelerated the vaccine development time, a larger commitment might prove more attractive than a smaller one.

Cost-effectiveness is sensitive to assumptions about the number of doses and the duration of protection. Vaccines with relatively low efficacy will still be cost effective if they can be delivered with the current (three-dose) EPI vaccine package, because adding one additional vaccine to this package is relatively inexpensive. In the baseline case, we have assumed a $\$ 0.75$ cost of adding a three-dose vaccine, although even at several multiples of this the delivery would be quite inexpensive. For example, assuming an incremental delivery cost of triple that amount (\$2.25 per person immunized) increases the cost per DALY saved to about $\$ 20$ if the set of countries included is held fixed, and augments the cost per DALY by only pennies if we assume that only countries in which the vaccine would be cost-effective at delivery cost adopt the vaccine. In contrast, delivery outside the EPI schedule would be relatively costly. For example, at our assumed cost of \$5 per dose, adding two doses outside of the EPI schedule would bring the cost per DALY to about $\$ 60$ per DALY saved if the set of participating countries is held constant, or about \$25 per DALY if countries with low disease burdens opt out because delivery of the vaccine would not be costeffective. 
Similarly, cost-effectiveness is sensitive to changing assumptions about the duration of protection. Because malaria primarily kills children under the age of five who have not yet gained natural immunity, the cost per DALY increases rapidly for vaccines that provide less than five years of protection. For example, if a vaccine provided only two years of protection, the cost per DALY saved would rise to $\$ 26$. A lesson to be learned from these sensitivity analyses is that, when specifying the product profile, any vaccine commitment for malaria should take these dosing and protection duration issues into account.

\section{Cost-effectiveness in the case of accelerated development and distribution}

The above calculations demonstrate that once a vaccine is developed, purchasing vaccine at the pre-specified price would be a very cost-effective expenditure. There is little reason to fear, therefore, that a vaccine commitment would tie donors to future purchases that would not be worthwhile, if a vaccine were developed. We now examine a somewhat more complex issue namely, the value of the commitment in accelerating the development and distribution of a vaccine. To assess this, we need to make assumptions about what would have happened in the absence of a commitment.

In the absence of a price commitment both development and adoption of the vaccine could be pushed further into the future. Although it is difficult to know how much a vaccine commitment would speed up vaccine development, one indication that the effect may be substantial comes from the Orphan Drug Act. While only ten new orphan drugs were discovered in the decade prior to the Orphan Drug Act, 200 were discovered in the next decade (Grabowski, 2003). A vaccine commitment is also likely to substantially accelerate access in the poorest countries since the sponsor's price is paid on a per-person immunized basis. In contrast, when the hepatitis B vaccine was introduced at \$30 per dose, it was rarely used in low-income countries (Muraskin, 1995; 
Galambos, 1995). More generally, the historical record suggests adoption of new vaccines in poor countries could be delayed by 10 to 15 years in the absence of a market commitment. ${ }^{28}$ Given the substantial burdens of diseases such as HIV, malaria, and tuberculosis, the health benefits of speeding development and adoption of such vaccines would be considerable.

If a vaccine market commitment advanced vaccine development by ten years and accelerated access in poor countries by ten years, it would still cost only about $\$ 23$ per additional DALY saved. Even in the extreme case in which a price commitment accelerated vaccine development by only one year and adoption in poor countries by only two years, the program would cost about \$80-\$90 per additional DALY saved—still slightly less than the oft-cited \$100 per DALY cost-effectiveness threshold for the poorest countries. The analogous figures for the larger commitment size we derived in the presence of a superiority clause are \$38 per additional DALY saved if the commitment advanced vaccine development by ten years and accelerated access in poor countries by ten years, and \$163 per additional DALY saved if the commitment accelerated vaccine development by only one year and adoption in poor countries by only two years. (These figures are all relative to the absence of any commitment.)

By a similar line of reasoning, if increases in the size of the commitment accelerated development of a vaccine, it may be worthwhile to undertake a larger commitment. As previously discussed, paying \$25 per person for the first 250 million people immunized rather than \$15 per person for the first 200 million people would roughly meet the average net present value of

\footnotetext{
${ }^{28}$ We estimate delays in access based on the historical record, but one could argue that the circumstances would be different now or in the future. However, if one believes that even in the absence of a commitment, donors would immediately buy a vaccine and distribute it at an on-patent price comparable to the initial price offered under the vaccine commitment, then the cost of purchasing and distributing the vaccine would be the same with or without a vaccine commitment, and any benefits of accelerated development associated with announcing a commitment in advance would be without cost in the ultimate price tag for a vaccine. In this case, if the money will be spent on the vaccine anyway, it is clearly more cost-effective to reap the benefits of faster development by announcing this policy in advance and entering into a vaccine commitment. Conversely, if one believes that companies would have to give away a vaccine in poor countries at cost, it is difficult to argue that a vaccine commitment would not be critical in advancing vaccine development.
} 
products between the 80th and 90th percentiles of existing commercial products. The larger commitment would cost less than $\$ 100$ per additional DALY saved if it advanced development and adoption by only three years relative to the smaller commitment, and would cost about \$23 per DALY saved overall.

It is also possible to ask what benefits -- in terms of faster vaccine development or gains in efficacy -- would make our larger market size estimate (with a superiority clause, \$5.24 billion) "worth it" in terms of the additional DALYs saved costing less than $\$ 100$. We estimate that a $10 \%$ increase in our benchmark efficacy assumption (that is, moving from $60 \%$ to $70 \%$ efficacy) would be worth it in this sense. Alternatively, if development and adoption of the vaccine were speeded by three years this larger market size would in this sense also be worthwhile.

\section{Conclusions}

A variety of simulations suggest that under a wide range of values, an advance market vaccine commitment may be sufficient to stimulate substantial research towards a desired vaccine, and from a public health perspective still be extremely cost-effective. Our estimates suggest that a commitment of \$3.1 billion in 2004 dollars in net present value of sales would be comparable to the value of sales earned by the average of a sample of recently launched commercial products, adjusted for lower marketing costs. Of course in expectation, the larger the commitment, the more biopharmaceutical firms will enter the search for a vaccine, and the faster a vaccine is likely to be developed. We have also discussed a number of other factors (such as the stage of product development, or the amount of $\mathrm{R} \& \mathrm{D}$ which has been financed directly) that donors may want to consider when designing the appropriate size of an advance market commitment.

We have focused here on the example of a malaria vaccine; however, as discussed throughout our general analysis applies more broadly. In particular, estimates for HIV and 
tuberculosis vaccines analogous to those presented here for malaria can be derived via the downloadable spreadsheet tool. 


\section{Table 1. Net present value (NPV) of sales}

\begin{tabular}{|c|c|c|c|c|c|}
\hline $\begin{array}{l}\text { Typical } \\
\text { product in } \\
\text { 1st decile }\end{array}$ & $\begin{array}{l}\text { Typical } \\
\text { product in } \\
\text { 2nd decile }\end{array}$ & $\begin{array}{l}\text { Typical } \\
\text { product in } \\
\text { 3rd decile }\end{array}$ & $\begin{array}{c}\text { Average } \\
\text { product in } \\
\text { entire sample }\end{array}$ & $\begin{array}{l}\text { Typical } \\
\text { product in } \\
\text { 4th decile }\end{array}$ & $\begin{array}{l}\text { Typical } \\
\text { product in } \\
\text { 5th decile }\end{array}$ \\
\hline 15.80 billion & 5.73 billion & 3.61 billion & 3.09 billion & 2.48 billion & 1.34 billion \\
\hline
\end{tabular}

Notes: All figures are in 2004 dollars. Figures have been adjusted down 10 percent for lower marketing costs.

Source: Grabowski et al. (2002) data, authors’ calculations. 
Figure 1.

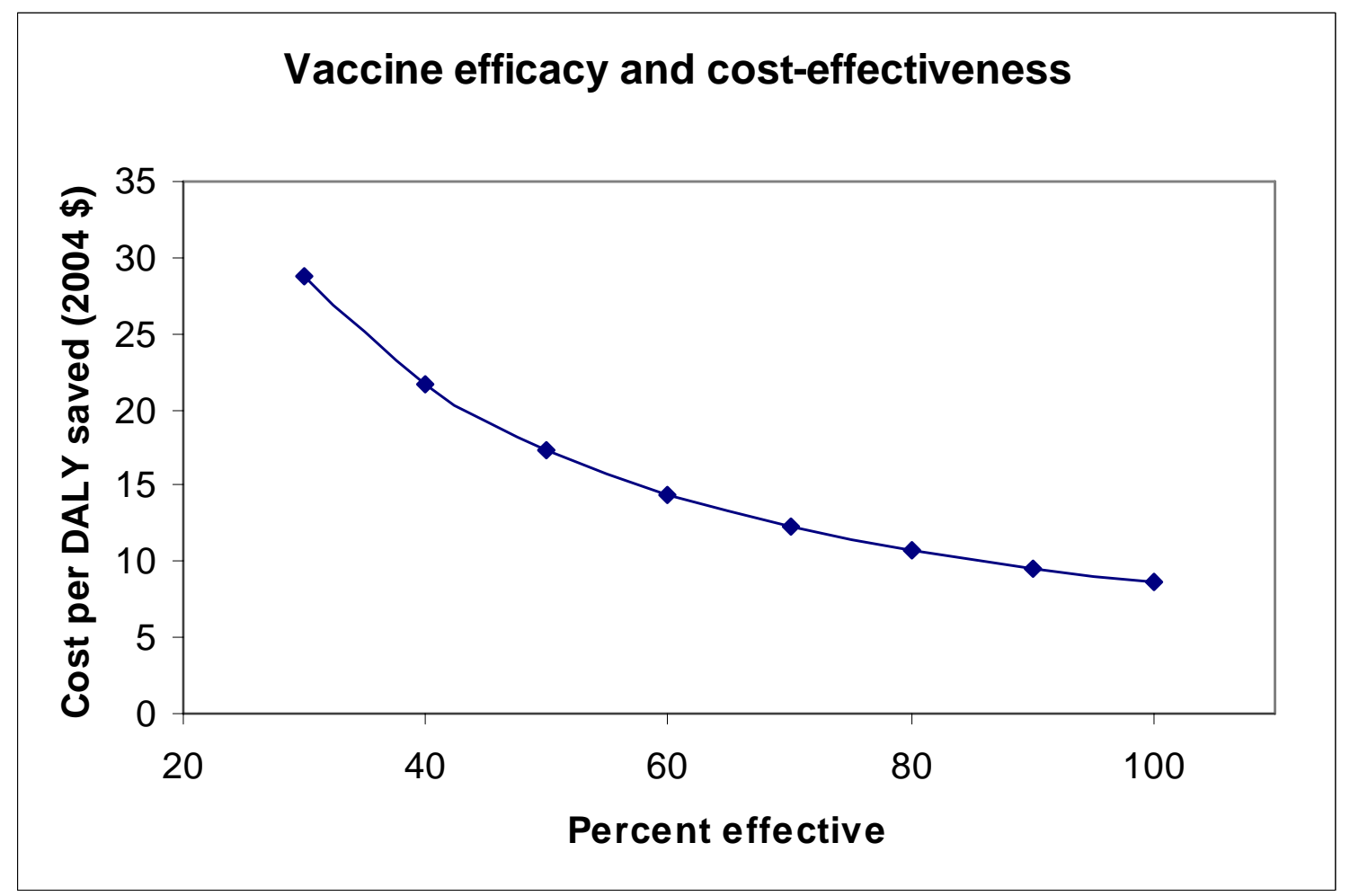




\section{Appendix}

This table presents the sales revenue data underlying our analysis in Section 3. Special thanks to Henry Grabowski for generously sharing this data with us.

\begin{tabular}{|c|c|c|c|c|c|c|}
\hline \multirow[b]{2}{*}{$\underline{\text { Year }}$} & \multicolumn{3}{|c|}{$\underline{\text { Mean Product }}$} & \multicolumn{3}{|c|}{ Product in Top Decile } \\
\hline & Sales & $\begin{array}{l}\text { NPV of Sales } \\
\text { (8\% real cost } \\
\text { of capital) }\end{array}$ & $\begin{array}{l}\text { NPV of Sales } \\
\text { (11\% real cost } \\
\text { of capital) }\end{array}$ & Sales & $\begin{array}{l}N P V \text { of Sales } \\
\text { (8\% real cost } \\
\text { of capital) }\end{array}$ & $\begin{array}{c}\text { NPV of Sales } \\
\text { (11\% real cost } \\
\text { of capital) }\end{array}$ \\
\hline$t=-1$ & 0.0 & 0.0 & 0.0 & 0.0 & 0.0 & 0.0 \\
\hline $\mathrm{t}=0$ & 0.0 & 0.0 & 0.0 & 0.0 & 0.0 & 0.0 \\
\hline t = 1 (launch) & 83.0 & 83.0 & 83.0 & 293.5 & 293.5 & 293.5 \\
\hline$t=2$ & 155.6 & 144.1 & 140.2 & 545.6 & 505.2 & 491.5 \\
\hline$t=3$ & 211.6 & 181.4 & 171.7 & 791.0 & 678.2 & 642.0 \\
\hline$t=4$ & 267.6 & 212.4 & 195.7 & 1094.8 & 869.1 & 800.5 \\
\hline$t=5$ & 325.7 & 239.4 & 214.5 & 1447.7 & 1064.1 & 953.6 \\
\hline$t=6$ & 371.6 & 252.9 & 220.5 & 1729.4 & 1177.0 & 1026.3 \\
\hline $\mathrm{t}=7$ & 414.7 & 261.3 & 221.7 & 2000.4 & 1260.6 & 1069.5 \\
\hline$t=8$ & 434.5 & 253.5 & 209.3 & 2200.5 & 1284.0 & 1059.9 \\
\hline$t=9$ & 457.4 & 247.1 & 198.5 & 2381.2 & 1286.5 & 1033.3 \\
\hline$t=10$ & 457.8 & 229.0 & 179.0 & 2503.5 & 1252.4 & 978.7 \\
\hline $\mathrm{t}=11$ & 444.4 & 205.8 & 156.5 & 2539.2 & 1176.1 & 894.3 \\
\hline$t=12$ & 441.4 & 189.3 & 140.0 & 2587.2 & 1109.6 & 820.9 \\
\hline$t=13$ & 416.2 & 165.3 & 119.0 & 2582.1 & 1025.4 & 738.1 \\
\hline$t=14$ & 391.8 & 144.1 & 100.9 & 2565.9 & 943.5 & 660.8 \\
\hline $\mathrm{t}=15$ & 307.8 & 104.8 & 71.4 & 1989.8 & 677.4 & 461.6 \\
\hline$t=16$ & 232.1 & 73.2 & 48.5 & 1486.0 & 468.4 & 310.6 \\
\hline $\mathrm{t}=17$ & 185.7 & 54.2 & 35.0 & 1188.8 & 347.0 & 223.8 \\
\hline$t=18$ & 148.5 & 40.1 & 25.2 & 951.0 & 257.0 & 161.3 \\
\hline$t=19$ & 118.8 & 29.7 & 18.2 & 760.8 & 190.4 & 116.3 \\
\hline$t=20$ & 95.1 & 22.0 & 13.1 & 608.6 & 141.0 & 83.8 \\
\hline sum & 5961.3 & 3132.8 & 2561.8 & 32247.0 & 16006.4 & 12820.2 \\
\hline Sum in $2004 \$$ & 6539.4 & 3436.6 & 2810.3 & 35374.3 & 17558.7 & 14063.5 \\
\hline $\begin{array}{l}\text { Less } 10 \% \\
\text { (for lower } \\
\text { marketing } \\
\text { expenditures) }\end{array}$ & 5885.5 & 3092.9 & 2529.3 & 31836.9 & 15802.8 & 12657.2 \\
\hline
\end{tabular}

Notes: All figures are in millions of year 2000 dollars, except as noted otherwise. The sales distribution for the mean product, as presented above, was scaled for several cases discussed in this paper such that the peak (year 10) sales were equal to the following: \$500 million for the "industry outsider" estimate, \$100 million for the outside-of-program purchases market estimate, and $\$ 865.2$ million for the hepatitis B vaccine market estimate. Details of these calculations are available upon request from the authors. 


\section{References}

Adams G et al. "Consensus Statement on Antiretroviral Treatment for AIDS in Poor Countries.” 2001. Available online: http://www.hsph.harvard.edu/bioethics/pdf/consensus_aids_therapy.pdf [accessed 30 May 2006]

Alonso P et al. "Efficacy of the RTS, S/AS02A Vaccine Against Plasmodium Falciparum Infection and Disease in Young African Children: Randomised Controlled Trial.” Lancet 2004, 364(9443): 1411-1420.

Angell M. The Truth About Drug Companies. Random House: New York, NY, 2004.

Ballou W et al. "Update on the clinical development of candidate malaria vaccines.” American Journal of Tropical Medicine and Hygiene 2004, 71(2 Supplement): 239-247.

Barder O et al. Making Markets for Vaccines. Center for Global Development: Washington, DC, 2005. Available online: http://www.cgdev.org/section/initiatives/_active/vaccinedevelopment/ [accessed 30 May 2006]

Berndt E, Hurvitz J. "Vaccine advance-purchase agreements for low-income countries: Practical issues.” Health Affairs 2005, 24(3): 653-665.

Berndt E et al. "Estimating the Required Volume of a Malaria Vaccine Commitment.” Mimeo: Cambridge, MA, 2003.

Bohrer R, Prince J "A tale of two proteins: The FDA's uncertain interpretation of the Orphan Drug Act.” Harvard Journal of Law \& Technology 1999, 12(2): 364-417.

Brown G. "Speech by the RT Gordon Brown MP, Chancellor of the Exchequer at the BBC World Service Trust conference.” 24 November, 2004. Available online: http://www.hmtreasury.gov.uk./newsroom_and_speeches/press/2004/press_94_04.cfm [accessed 30 May 2006]

DiMasi J et al. “The Price of Innovation: New Estimates of Drug Development Costs.” Journal of Health Economics 2003, 22: 151-185.

Finkelstein A. "Static and Dynamic Effects of Health Policy: Evidence from the Vaccine Industry." Quarterly Journal of Economics 2004, 119(2): 527-564.

G8 Information Centre. "G7/G8 Summit Meetings, St. Petersburg Summit Documents: Fight Against Infectious Disease.” 2006. Available online:

http://www.g7.utoronto.ca/summit/2006stpetersburg/infdis.html [accessed 23 July 2006]

Galambos L. Networks of Innovation: Vaccine Development at Merck, Sharp \& Dohme, and Mulford, 1895-1995. Cambridge University Press: Cambridge, 1995.

Global Alliance for Vaccines and Immunization (GAVI). "Health, Immunization, and Economic Growth, Research Briefing \#2, Vaccines are Cost-effective: A Summary of Recent Research.” 2004. Available online: 
http://www.gavialliance.org/General_Information/Immunization_informa/Economic Impact/vacc cost.php [accessed 30 May 2006]

Grabowski H. "Increasing R\&D Incentives for Neglected Diseases - Lessons from the Orphan Drug Act.” Mimeo: Duke University, 2003.

Grabowski H, Vernon J. “A New Look at the Returns and Risks to Pharmaceutical R\&D.” Management Science 1990, 36: 804-821.

Grabowski H, Vernon J, DiMasi J. "Returns on Research and Development for 1990s New Drug Introductions.” PharmacoEconomics 2002, 20 (Supplement 3): 11-29.

HM Treasury. "Statement by G7 Finance Ministers and Central Bank Governors.”2-3 December, 2005. Available online: http://www.hmtreasury.gov.uk/otherhmtsites/g7/news/g7 statement 031205.cfm [accessed 30 May 2006]

Kremer M, Glennerster R. Strong Medicine: Creating Incentives for Pharmaceutical Research on Neglected Diseases. Princeton University Press: Princeton, NJ, 2004.

McNeil D. "Plan to Bring Generic AIDS Drugs to Poor Nations.” New York Times 2004, April 6: F06.

Muraskin W. The War Against Hepatitis B: A History of the International Task Force on Hepatitis B Immunization. University of Pennsylvania Press: Philadelphia, PA, 1995.

Neumann P et al. "Are Pharmaceuticals Cost-Effective? A Review of the Evidence.” Health Affairs 2000, 19(2): 92-109.

Reuters. “Pfizer Announces Potential Malaria Discovery.” June 17, 2003.

Rin-Laures L-H, Janofsky D “Recent developments concerning the Orphan Drug Act.” Harvard Journal of Law \& Technology 1991, 4(Spring): 269-299.

Robbins-Roth C. From Alchemy to IPO: The Business of Biotechnology. Perseus Publishing: Boulder, CO, 2000.

Rosenthal M et al. "Promotion of Prescription Drugs to Consumers." New England Journal of Medicine 2002, 346(7): 498-505.

Siegal J. Stocks for the Long Run. McGraw Hill: New York, NY, 1998.

United States Bureau of the Census. International Data Base, Table 028: “Age-Specific Fertility Rates and Selected Derived Measures.” 2000. Available online: http://www.census.gov/ipc/www/idbnew.html [accessed 30 May 2006]

World Bank. Disease Control Priorities in Developing Countries. Oxford Medical Publications, Oxford University Press for the World Bank: New York, NY, 1993. 
World Bank. World Development Indicators. World Bank: Washington, DC, 2005.

World Health Organization (WHO). Investing in Health Research and Development: Report of the Ad Hoc Committee on Health Research Relating to Future Intervention Options. WHO: Geneva, 1996.

World Health Organization (WHO). “World Malaria Situation in 1994, Part I.” Weekly Epidemiological Record 1997, 72(36): 269-274.

World Health Organization (WHO). "Less-Used Vaccines against Major Diseases Are CostEffective, Researchers Conclude.” Bulletin of the World Health Organization 2000, 78(2): 274.

World Health Organization (WHO). World Health Report 2000. WHO: Geneva, 2000.

World Health Organization (WHO). World Health Report 2001. WHO: Geneva, 2001.

World Health Organization. "Vaccines, Immunizations, and Biologicals: Statistics and Graphs." 2002. Available online: http://www.who.int/vaccines-surveillance/StatsAndGraphs.htm [accessed 31 March 2006] 